\title{
TEORES DE Na, K, Mg E Ca EM PORTA-ENXERTOS DE VIDEIRA EM SOLUÇÃO SALINA
}

\author{
Alexandre Pio Viana ${ }^{1 *}$; Claudio Horst Bruckner²; Herminia Emilia Prieto Martinez²; Carlos Alberto \\ Martinez y Huaman ${ }^{3}$; Paulo Roberto Mosquim ${ }^{3}$ \\ ${ }^{1}$ Pós-Graduando em Produção Vegetal - UENF, Av. Alberto Lamego, 2000 - CEP: 28015-620 - Campos de \\ Goytacazes, RJ. \\ ${ }^{2}$ Depto. de Fitotecnia - UFV - CEP: 36571-000 - Viçosa, MG. \\ ${ }^{3}$ Depto. de Biologia Vegetal - UFV. \\ *Autor correspondente <pirapora@rol.com.br.>
}

\begin{abstract}
Resumo: Com o objetivo de avaliar a tolerância de porta-enxertos de videira à condições de salinidade, realizouse um ensaio, em casa de vegetação, com cinco cultivares de porta-enxertos ('IAC 766 Campinas', 'IAC 313 Tropical', 'IAC 572 Jales', '420-A' e 'Ripária do Traviú'), cultivadas em solução nutritiva, com cinco níveis de $\mathrm{NaCl}\left(0,5,10,15\right.$ e $\left.20 \mathrm{mmol} \mathrm{L}^{-1}\right)$. Foram determinados os teores de sódio, potássio, magnésio e cálcio no material vegetal. Os cultivares apresentaram padrões diferenciados, no tocante às concentrações dos nutrientes, nos diversos órgãos analisados (raiz, caule, folhas superiores e inferiores). As mais sensíveis, como a '420-A' e 'IAC 313', alocaram grande quantidade de $\mathrm{Na}$ nas folhas e apresentaram restrições na absorção de $\mathrm{K}, \mathrm{Mg}$ e Ca, em folhas e caules. As mais tolerantes ('IAC 766', 'IAC 572' e 'Ripária do Traviú') apresentaram maior retenção de $\mathrm{Na}$ nas raízes e nos caules, apresentando, uma pequena redução nos teores de $\mathrm{K}, \mathrm{Mg}$ e Ca nos demais órgãos.

Palavras-chave: videira, porta-enxertos, salinidade, tolerância, nutrientes
\end{abstract}

\section{$\mathrm{Na}, \mathrm{K}, \mathrm{Mg}$ AND Ca CONCENTRATIONS OF GRAPE-VINE ROOTSTOCK IN SALINE SOLUTION}

\begin{abstract}
In order to evaluate the tolerance of five grape-vine rootstock varieties ('IAC 766 Campinas', 'IAC 313 Tropical', 'IAC 572 Jales', '420-A' e 'Ripária do Traviú') in relation to salinity conditions, an experiment was conducted in a greenhouse using, five nutritient solutions with $\mathrm{NaCl}$ levels of $0,5,10,15$ and $20 \mathrm{mmol} \mathrm{L}^{-1}$. The concentrations of sodium, potassium, magnesium and calcium were determined in the shoot These varieties showed differentiated patterns regarding nutrient concentrations in the different plant compartments. The more sensitive ones '420-A' and 'IAC 313', allocated a large amount of $\mathrm{Na}$ to the leaves and presented restrictions to accumulate $\mathrm{K}, \mathrm{Mg}$ and $\mathrm{Ca}$ in stems and leaves. The more tolerant, 'IAC 766', 'IAC 572' and 'Ripária do Traviú', presented a greater retention of $\mathrm{Na}$ in roots and stems, maintaining a small reduction of $\mathrm{K}, \mathrm{Mg}$ and $\mathrm{Ca}$ concentrations in the other compartments.

Key words: grape-vine, rootstocks, salinity, tolerance, nutrient
\end{abstract}

\section{INTRODUÇÃO}

A viticultura de mesa vem tomando grande expansão nas regiões semi-áridas brasileiras. São áreas onde fatores como temperatura e luminosidade favorecem a produção de uva de mesa fora das épocas tradicionais e de qualidade superior.

Entretanto, problemas de salinização do solo já são evidentes em tais áreas, uma vez que o manejo de irrigação e adubação inadequados favorecem 0 aparecimento de tal degradação ambiental.

A salinização leva ao desbalanço nutricional, uma vez que o excesso de sais ( $\mathrm{Na} \mathrm{e} \mathrm{Cl}$ ) na solução do solo leva à uma distúrbio na absorção de nutrientes, alterando as concentrações de nutrientes, como $\mathrm{Ca}, \mathrm{K}, \mathrm{Mg}$ e $\mathrm{Na}$ na planta. Essa desordem nutricional pode levar a um desenvolvimento abaixo do normal, o que é afetado, em grande parte, pelos processos metabólicos da planta.
Os porta-enxertos utilizados nas regiões semiáridas brasileiras são, em sua maioria, introduções advindas do Estado de São Paulo, onde o Instituto Agronômico obteve, com sucesso, híbridos, adaptados e resistentes à filoxera. Este trabalho teve como objetivo avaliar os teores de $\mathrm{Na}, \mathrm{K}, \mathrm{Ca}$ e $\mathrm{Mg}$ e sua alocação nos tecido de vários órgãos de cinco porta-enxertos de videira submetidos a condições de salinidade, em solução nutritiva.

\section{MATERIAL E MÉTODOS}

Instalou-se um ensaio em casa de vegetação, no Departamento de Fitotecnia, da Universidade Federal de Viçosa (UFV), onde foram avaliados cinco porta-enxertos ('IAC 766 Campinas', 'IAC 313 Tropical', 'IAC 572 Jales', '420-A' e 'Ripária do Traviú'). Os porta-enxertos foram fornecidos pelo Instituto Agronômico de Campinas. O ensaio seguiu esquema fatorial $5 \times 5$ (cinco cultivares e 
cinco níveis de $\mathrm{NaCl}$ ), em delineamento em blocos casualizados, com três repetições. A parcela constou de um vaso, contendo duas plantas.

As estacas dos porta-enxertos foram enraizadas em leito de areia irrigada com solução nutritiva, formulada com base na concentração de macronutrientes na matéria seca obtida por Terra (1989), porém, diluída à metade. Após esse período, as mudas foram transferidas para solução nutritiva contendo $4,0 \mathrm{mmol} \mathrm{L}^{-1}$ de $\mathrm{K}^{+} ; 3,50$ $\mathrm{mmol} \mathrm{L}^{-1} \mathrm{Ca}^{+2} ; 0,80 \mathrm{mmol} \mathrm{L}^{-1}$ de $\mathrm{H}_{2} \mathrm{PO}_{4} ; 1,0 \mathrm{mmol} \mathrm{L}^{-1} \mathrm{de}$ $\mathrm{SO}_{4}^{2-;} ; 2,0 \mathrm{mmol} \mathrm{L}^{-1} \mathrm{Mg}^{2+} ; 12,2 \mathrm{mmol} \mathrm{L}^{-1} \mathrm{NO}_{3} ; 40 \mu \mathrm{mol} \mathrm{L}^{-1}$ de Fe; $20 \mu \mathrm{mol} \mathrm{L}^{-1}$ de $\mathrm{Mn} ; 3,0 \mu \mathrm{mol} \mathrm{L}^{-1}$ de $\mathrm{Zn} ; 40 \mu \mathrm{mol} \mathrm{L}^{-1}$ de $B ; 0.5 \mu \mathrm{mol} \mathrm{L}^{-1}$ de $\mathrm{Cu} ; 0.5 \mu \mathrm{mol}$. $\mathrm{L}^{-1}$ de Mo. Procedeuse a aclimatação durante o período de três semanas, sendo, logo em seguida, aplicados os tratamentos.

Para estimar as concentrações de cloreto de sódio necessárias para atingir as condutividades elétricas (CE) e pressões osmóticas $(\pi)$ de trabalho, realizaram-se curvas de calibração, adicionando-se à solução nutritiva $0,20,40$, 60 , 80 e $100 \mathrm{mmol} \mathrm{L}^{-1}$ de $\mathrm{NaCl}$, com três repetições. Nessas soluções, determinaram-se a CE com um condutivímetro "Analiser modelo 650" e a $\pi$ com um osmômetro de precisão marca "Osmette". De posse das equações de regressão ajustadas, determinaram-se as concentrações de $\mathrm{NaCl}$ para os tratamentos, que foram de $0,5,10,15$ e $20 \mathrm{mmol} \mathrm{L}^{-1}$ de $\mathrm{NaCl}$, correspondentes a

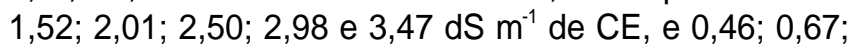
0,$89 ; 1,11 ; 1,33$ atm de $\pi$. Foram ajustadas as seguintes equações de regressão: $C E=1,5250+0,0971 \mathrm{NaCl}$ $\left.9 R^{2}=0,99\right), \pi=0,46+0,0436 \mathrm{NaCl}\left(R^{2}=0,99\right) .0 \mathrm{pH}$ da solução foi mantido em $5,5 \pm 0,1$ com controle diário, corrigido com $\mathrm{NaOH}$ ou $\mathrm{HCl} 1 \mathrm{~N}$. A solução nutritiva foi renovada sempre que os níveis de potássio atingiam $50 \%$ da concentração inicial. As plantas foram submetidas aos tratamentos durante 33 dias.

Para determinar a concentração dos elementos de cátions no material vegetal, as plantas foram separadas em raiz, caule e folhas. As partes foram devidamente lavadas com água desmineralizada, para retirada de impurezas externas; identificadas; secas em estufa de circulação forçada de ar, a $70-75^{\circ} \mathrm{C}$, até atingirem o peso constante; pesadas e moídas em moinho tipo "Wiley". Posteriormente, foram submetidas a digestão nítricoperclórica, determinando-se a concentração de $\mathrm{K}$ a Na por fotometria de chama, e $\mathrm{Ca}$ e $\mathrm{Mg}$ por espectrofotometria de absorção atômica.

\section{RESULTADOS E DISCUSSÃO}

Houve efeito de doses de $\mathrm{NaCl}$, e interação dose $x$ cultivares nas diversas partes da planta estudadas. $O$ acúmulo de sódio nas diferentes partes da planta, em função do nível de $\mathrm{NaCl}$ na solução nutritiva, variou entre os cultivares estudadas.

No cultivar 'IAC 313' (Figura 1), o teor variou segundo equação quadrática na raiz, havendo um acúmulo máximo no nível de $11,40 \mathrm{mmol} \mathrm{L}^{-1}$ de $\mathrm{NaCl}$, correspondendo a 0,51 dag $\mathrm{Kg}^{-1}$ no tecido. Os teores de potássio na raiz da IAC 313 diminuíram-se, à medida que a salinidade aumentou, seguindo equação linear (Figura 1).

Os teores de cálcio, na raiz da 'IAC-313', diminuíram, à medida que a salinidade aumentou, seguindo equação linear. Nas folhas superiores, os teores seguiram equação quadrática em função das doses de $\mathrm{NaCl}$ na solução nutritiva, com ponto de máximo na dose de 9,37 $\mathrm{mmol} \mathrm{L}^{-1}$ de $\mathrm{NaCl}, 1,88$ dag $\mathrm{Kg}^{-1}$ no tecido (Figura 1).

No cultivar 'IAC 766' (Figura 2), o Na acumulouse, seguindo uma equação linear, nas raízes, e mantevese constante nos demais órgãos, indicando que as raízes foram capazes de reter o elemento, evitando que o mesmo interferisse nos processos fisiológicos da parte aérea.

No cultivar '420-A' (Figura 3), houve aumento do teor de $\mathrm{Na}$, seguindo equação linear nas raízes e variação, seguindo equação quadrática, dos teores no caule e nas folhas inferiores, com pontos de máximo nos níveis de 13,0 mmol $\mathrm{L}^{-1}$ e $9,57 \mathrm{mmol} \mathrm{L}^{-1}$, respectivamente, correspondendo a 0,52 dag $\mathrm{Kg}^{-1}$ e 0,28 dag $\mathrm{Kg}^{-1}$, respectivamente, no tecido, indicando que, no cultivar ' 420 A', não houve mecanismo que evitasse a entrada de $\mathrm{Na}$ nas regiões fotossinteticamente ativas, o que permitiria classificá-la como não-tolerante.

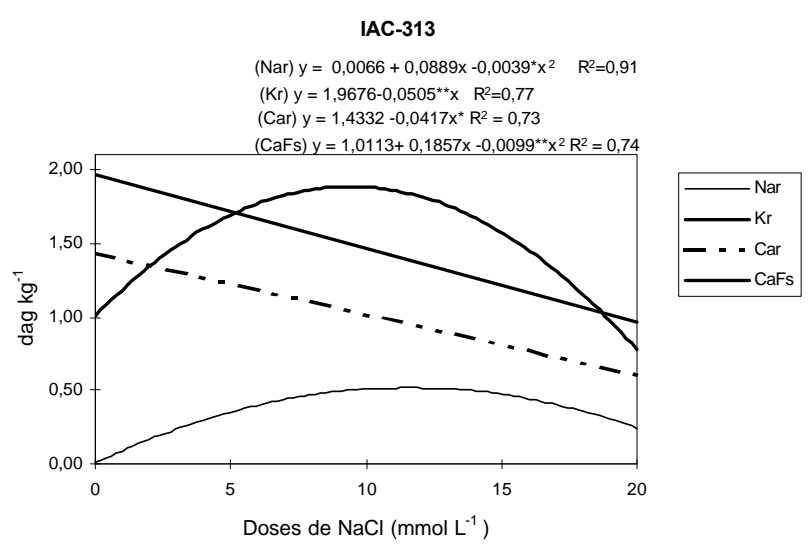

Figura 1 - Tores de Sódio na raiz (Nar), teores de Cálcio na raiz Car) e folhas superiores (CaFs), e tores de Potássio na raiz $(\mathrm{Kr})$ do cultivar IAC 313, como variável da doses de $\mathrm{NaCl}$.

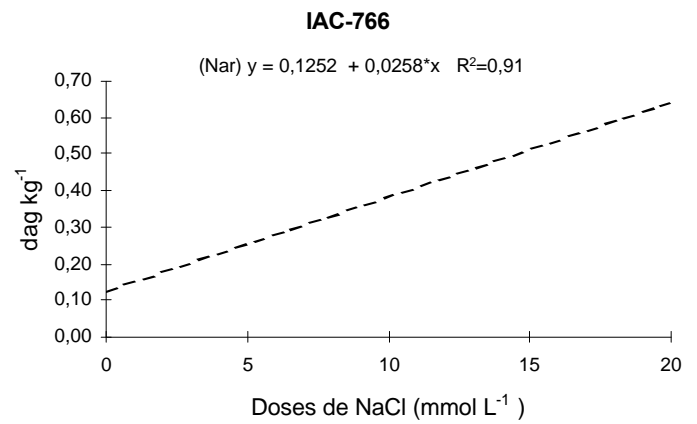

Figura 2 - Teores de Sódio na raiz (Nar), no cultivar IAC 766, como variável da doses de $\mathrm{NaCl}$. 
$\mathrm{Na}$ '420-A', o teor de potássio nas folhas inferiores, seguiu um comportamento quadrático, com aumento até a dose de $8,29 \mathrm{mmol} \mathrm{L}^{-1}$ de $\mathrm{NaCl}$, correspondendo a 2,19 dag kg-1 no tecido (Figura 3).

$O$ teor de magnésio nas folhas inferiores, seguiu um comportamento quadrático, com ponto de máximo na dose de $8,13 \mathrm{mmol} \mathrm{L}^{-1}$ de $\mathrm{NaCl}$, correspondendo a 0,12 dag $\mathrm{Kg}^{-1}$ no tecido (Figura 3).

No cultivar 'IAC 572' (Figura 4), houve aumento do teor de $\mathrm{Na}$, com o aumento de $\mathrm{NaCl}$ na solução nutritiva, seguindo-se equação linear, principalmente no caule e também nas raízes e folhas inferiores. Isso indica que pode haver tolerância desse cultivar à salinidade, com retenção de Na no caule da planta.

Para o potássio não foram observadas diferenças significativas entre os tratamentos no caule e nas folhas inferiores e superiores. Para a raiz, a resposta foi linear, apresentando redução com o incremento das doses de $\mathrm{NaCl}$ na solução nutritiva (Figura 4).

$\mathrm{Na}$ 'IAC 572', para o cálcio, não se observaram diferenças significativas entre os tratamentos para a raiz, o caule e as folhas superiores. Nas folhas inferiores, observou-se resposta linear descendente (Figura 4).

No cultivar 'Ripária do Traviú' (Figura 5), observase aumento linear do teor de $\mathrm{Na}$ nas raízes. Com o aumento de $\mathrm{NaCl}$ na solução nutritiva, não foram verificadas alterações nos teores nas folhas inferiores, superiores e no caule. Isso indica um possível mecanismo de tolerância, associado à retenção de Na nas raízes.

Os resultados encontrados em todas os cultivares não estão de acordo com os encontrados por Harvey \& Stevens (1995), que não observaram diferenças significativas nos teores de sódio nas raízes, com 0 incremento da salinidade em videiras. Bhivare \& Nimbalkar (1984) verificaram incremento de sódio em raízes de feijão, com o aumento de $\mathrm{NaCl}$ na solução de crescimento, e sugeriram que isso o excluiria das folhas. Tais resultados corroboram os de Prior et al. (1992a); West \& Taylor (1984); e Alexander \& Groot (1971), que detectaram uma alocação preferencial de sódio em caules de videiras.

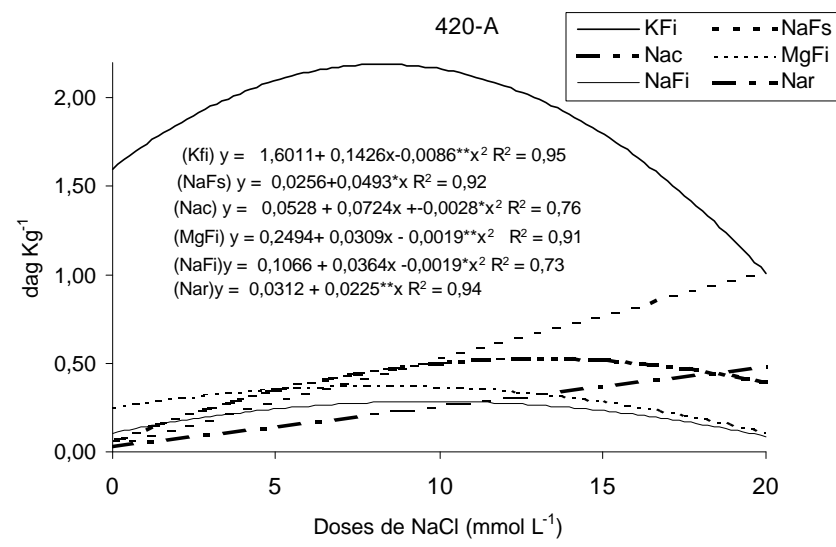

Figura 3 - Teores de Sódio na raiz (Nar), caules (Nac), folhas inferiores $(\mathrm{NaFi})$, folhas superiores (NaFs), Potássio nas folhas inferiores (KFi) e Magnésio nas folhas inferiores (MgFi) no cultivar 420-A, como variável das doses de $\mathrm{NaCl}$.

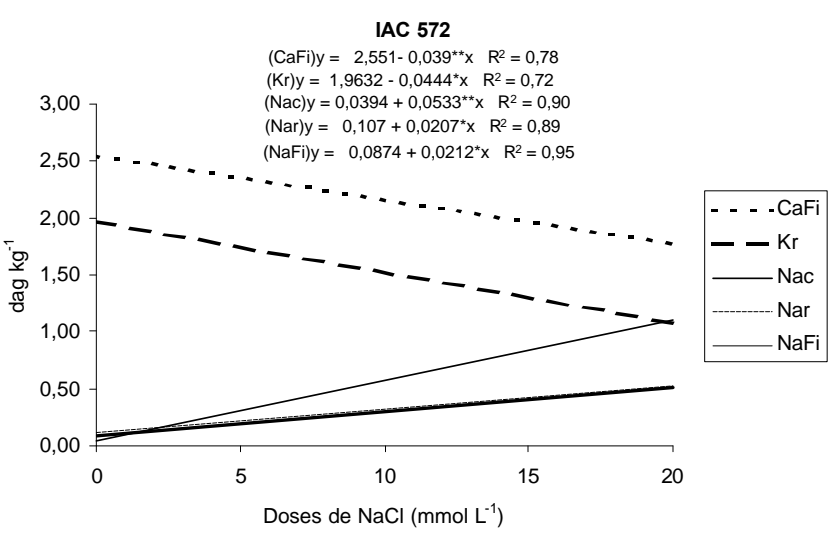

Figura 4 - Teores de Sódio na raiz (Nar), caules (Nac), folhas inferiores ( $\mathrm{NaFi})$, Potássio na raiz ( $\mathrm{Kr}$ ) e Cálcio nas folhas inferiores (CaFi), no cultivar IAC 572, como variável de doses de $\mathrm{NaCl}$.

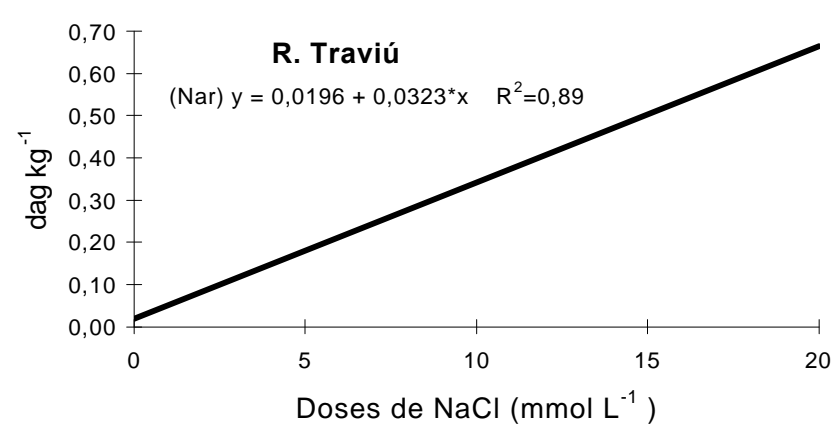

Figura 5 - Teores de Sódio na raiz (Nar), do cultivar Ripária do Traviú, como variável de doses de $\mathrm{NaCl}$

O fato de o cultivar 'IAC 572' não apresentar alocação de sódio nas raízes, e ser tão tolerante quanto a 'IAC 766' e 'Ripária do Traviú', indica que a capacidade de reter sódio, especificamente, no caule, também é fator importante no tocante à maior ou menor tolerância. Isso, provavelmente, dar-se-ia pela transferência lateral do sódio da seiva inorgânica para células do parênquima do xilema e, ou, pela adsorção destes às cargas negativas das paredes dos vasos xilemáticos no caule (Rains, 1969).

O sódio exerce prejuízos ao ambiente celular, uma vez que exerce uma série de efeitos tóxicos, por meio da inibição de reações enzimáticas. Uma inadequada compartimentalização desse elemento, entre citoplasma e vacúolo, leva a uma desidratação e conseqüente diminuição da turgescência da célula, o que pode provocar morte celular em folhas e ramos (Marschner, 1995).

As plantas normalmente requerem grande quantidade de potássio. As células do córtex da raiz, por meio de suas membranas, têm uma alta afinidade pelo transporte de potássio ou sódio, sendo que esse grau de seletividade pode variar drasticamente de acordo com a espécie (Grattan \& Grieve, 1993). 
Várias espécies absorvem e translocam potássio, em preferência ao sódio, mas nas espécies mais sensíveis essa afinidade é reduzida, uma vez que, quando crescem em substratos com altos níveis de $\mathrm{NaCl}$, o teor de potássio no tecido vegetal é sensivelmente reduzido (Pugnaire et al., 1993).

Apesar de o sódio substituir o potássio no ajustamento osmótico vacuolar, o mesmo parece não ocorrer com a geração de turgor estomatal, o que, presumivelmente, reflete a operação de um transporte específico e direcional de íons altamente seletivos para o potássio. A seletividade do sistema de transporte de potássio sobre o sódio fornece uma limitação fundamental no grau em que o sódio substituirá o potássio nas plantas e o aparente requerimento de potássio para a exclusão de sódio. Essa variação pode resultar na elevação do sódio citoplasmático e, também, por conseqüência do vacuolar e do transportado para o xilema (Flowers \& Lauchli, 1983). Isso indica que, para o grupo estudado, a maior tolerância dos cultivares, como da 'IAC 572', 'Ripária do Traviú' e 'IAC 766', está relacionada à manutenção ou ao aumento dos teores de potássio nas folhas, mesmo com 0 aumento da salinidade, o contrário acontecendo com a '420-A' e 'IAC 313'.

Prior et al. (1992a) e Downton (1977), trabalhando com videiras, obtiveram redução nos teores de potássio em folhas de plantas sujeitas a ambiente salino. Já Harvey \& Stevens (1995) não constataram diferenças significativas nos teores de potássio em folhas de videiras, quando essas foram submetidas a condições de salinidade e a baixa aeração no solo (encharcamento).

O magnésio exerce funções importantes na célula vegetal, que vão desde a síntese de proteínas e clorofilas, ativação enzimática, fosforilação, fotossíntese, até a partição de carbono no tecido vegetal, uma vez que, em plantas deficientes em magnésio, a queda na capacidade fotossintética altera o suprimento de fotoassimilados, alterando as relações fonte/dreno (Marschner, 1995).

Deficiência de magnésio pode ser induzida, em plantas estressadas por sais, o que reduz o crescimento da planta, por alteração da razão cálcio/magnésio, acarretando queda da razão de fotossíntese e declínio na eficiência do uso de água (Grattan \& Grieve, 1993).

Os resultados obtidos estão parcialmente de acordo com os de Prior et al. (1992a, 1992b) que, trabalhando com videiras estressadas por sais, não observaram reduções nos teores de magnésio nas folhas.

$O$ aumento da salinidade reduz a concentração de cálcio, uma vez que reduz o influxo desse elemento em raízes de plantas sujeitas a essa condição de ambiente. $O$ desbalanço nutricional atua de modo decisivo, o excesso de sódio inibe o movimento radial de cálcio da solução externa, até o xilema das raízes, afetando a troca de cátions nos sítios do apoplasto (Grattan \& Grieve, 1993).
Os resultados obtidos estão de acordo com os encontrados por Kramer \& Boyer (1995), que verificaram que a primeira resposta ao estresse por $\mathrm{NaCl}$, em raízes de algodoeiro, seria a menor seletividade da membrana, por sua desorganização, associada ao desequilíbrio entre cálcio e sódio, o que diminuiria sua seletividade ao potássio.

Nas folhas de todas os cultivares, os teores de cálcio tenderam a se modificar. Esse comportamento parece depender da entrada de sódio nas folhas. O teor de cálcio é, aparentemente, inversamente proporcional ao de sódio. Assim, enquanto os teores de sódio aumentaram nas folhas dos cultivares 'IAC 313', 'IAC 572', 'IAC 766', '420-A' e 'Ripária do Traviú', para salinidades maiores que $15 \mathrm{mM} \mathrm{L}^{-1}$ de $\mathrm{NaCl}$, os de cálcio decresceram.

Em contraste aos outros macronutrientes, uma alta proporção de cálcio no tecido vegetal é alocada nas paredes celulares (apoplasto). Essa distribuição única, comumente, resulta de abundantes sítios de troca para o cálcio na parede celular (Marschner, 1995).

\section{CONCLUSÕES}

Os cultivares 'IAC 572', 'IAC 766' e 'Ripária do Traviú', que se mostraram mais tolerantes, conseguiram excluir preferencialmente $0 \mathrm{Na}$ das regiões metabolicamente ativas, alocando-o, preferencialmente na raíz ou no caule.

Os cultivares mais sensíveis, 'IAC 313' e '420-A', alocaram grande quantidade de $\mathrm{Na}$ nas folhas $\mathrm{e}$ apresentaram restrições na absorção da K, Mg e Ca.

\section{REFERÊNCIAS BIBLIOGRÁFICAS}

ALEXANDER, D.E.; GROOT, O.J. Effect of chloride in solution culture on growth and chloride uptake of Sultana and Salt creet grape vines. Australian Journal of Experimental Agricultural and Animal Husbandry, v.2, p.357-361, 1971.

BHIVARE, V.N.; NIMBALKAR, J.D. Salt stress on growth and mineral nutrition of french beans. Plant and Soil, v.80, p.91-98, 1984.

DOWNTON, W.J.S. Influence of rootstock on the accumulation of chloride, sodium and potassium in grapevines. Australian Journal of Plant Physiology, v.4, p. 879-889, 1977.

FLOWERS, T.J.; LAUCHLI, A. Inorganic plant nutrition. New York: Springer-Verlag, 1983. 681p.

GRATTAN, S.R.; GRIEVE, C.M. Mineral nutrient acquisition and response by plants grown in saline environments. In: PESSARAKLI, P. Handbook of plant and crop stress. New York: Marcel Dekker, 1993 . p203-225.

HARVEY, G.; STEVENS, R.M. Effects of waterlogging, rootstock and salinity on $\mathrm{Na}, \mathrm{Cl}$ and $\mathrm{K}$ concentrations of the leaf and root, and shoot growth of Sultana Grapevines. Australian Journal of Agricultural Research, v. 46, p. 541-551, 1995.

KRAMER, P.J.; BOYER, J.S. Water relations of plants and soils. London: Academic Press, 1995. 495p.

MARSCHNER, H. Mineral nutrition of higher plants. 2.ed. San Diego: Academic Press, 1995. 680p.

PRIOR, L.D.; GREIVE, A.M.; CULLIS, B.R. Sodium chlorine and soil texture interactions in irrigated field growth sultana grapevines: II. Plant mineral content, growth and physiology. Australian Journal of Agricultural Reserch v.43, p.1051-1066, 1992a. 
PRIOR, L.D.; GREIVE, A.M.; CULLIS, B.R. Sodium chlorine and soil texture interactions in irrigated field growth sultana grapevines: III. Soil and root system effects. Australian Journal of Agricultural Resserch, v.43, p.1051-1066, 1992b.

PUGNAIRE, F.I.; ENDOLZ,L.S.; PARDOS, J. Constrains by water stress on plant growth. In: PESSARAKLI, P. Handbook of plant and crop stress. New York : Marcel Dekker, 1993. p.247-259.

RAINS, D.W. Cation absorption by slice of stem tissues of beans and cotton. Experientia, v.25, p.215-216, 1969.
TERRA, M. M.. Seis anos de experimentação de adubação (NPK) em Videira Niagara rosada vegetando em um solo podzolizado. Piracicaba, 1989. 87p. Tese (Doutorado) - Escola Superior de Agricultura "Luiz de Queiroz", Universidade de São Paulo.

WEST, D.W.; TAYLOR, J.A. Reponse of six grape cultivars to the combined effects of high salinity and rootzone waterlogging. Journal of the Americam Society for Horticultural Science, v.109, p.844-851, 1984.

$\overline{\text { Recebido em } 17.08 .00}$ 